\title{
SIGNIFICANCE OF POSTURE AND POSITION IN THE COMMUNICATION OF ATTITUDE AND STATUS RELATIONSHIPS ${ }^{1}$
}

\author{
ALBERT MEHRABIAN 2 \\ University of California, Los Angeles
}

\begin{abstract}
The present paper attempts to present a review of the experimental findings dealing with the posture and position of a communicator relative to his attitude and status to his addressee. More studies are available which exhibit the detailed functional relationships of posture and position variables to communicator attitudes than to communicator-addressee relative status. Distance, eye contact, body orientation, arms-akimbo position, and trunk relaxation have been found most consistently to be indicators of communicator attitude toward an addressee. These variables along with the degree of arm openness of female communicators and degree of asymmetry in the arrangement of arms and legs have been found or hypothesized to be associated with status relationships with the addressee.
\end{abstract}

The present paper is an attempt to summarize investigations of the significance of the posture, distance, and orientation of communicators toward addressees as possible indicators of communicator attitude and status relative to the addressee. For the purposes of discussion, attitude is broadly defined as the degree of liking, positive evaluation, and/or preference of one person for another.

Findings of such studies can be applied to infer attitudes in interviews or research settings where the researcher is interested in inferring the attitude of his subject, whose explicit verbalizations of attitude are of doubtful validity. For instance, the independent assessment of attitudes as they are communicated by posture and position cues can allow the measurement of the degree of inconsistency in the attitude communications of an individual, such as between posturally communicated attitudes and verbally communicated attitudes (e.g., Beakel \& Mehrabian, 1969). Furthermore, since in a number of everyday communication situations the communication of attitudes in an overt manner is culturally discouraged, the use of nonverbal cues can be a valuable means of determining the attitude of a communicator.

1 This research was supported by United States Public Health Service Grant MH 13509.

${ }^{2}$ Requests for reprints should be sent to Dr. Albert Mehrabian, Department of Psychology, University of California, Los Angeles, Los Angeles, California 90024 .
It was in contexts where overt expressions of attitude were not possible that the significance of nonverbal cues in attitude communication was initially denoted by psychoanalysts. Posture was used as a source of information about clients' characteristics, feelings, and attitudes toward others and themselves. Informal writings based on case studies are exemplified by the work of Deutsch $(1947,1952)$, who noted that the posture of a client relates to his motivations, attitudes, and intentions, which may or may not be verbalized, and that characteristic postures are associated with the initiation and termination of speech. Deutsch and Murphy (1955) provided a number of specific examples whereby feelings and attitudes of clients were inferred from their postures. Reich (1945) and Braatoy (1954) denoted postural rigidity or tension as an important indicator of the correlated degree of difficulty encountered in the manipulation of client characteristics. In agreement with Reich and Braatoy, Lowen (1958) suggested that a client's characteristics are closely intertwined with characteristic postures and gestures, and therefore the manipulation of client characteristics can be enhanced through the manipulation of the latter. Like Deutsch and Murphy (1955), Fromm-Reichmann (1950) employed the changing postures of her clients to infer their feelings. She imitated the postures of her clients in order to 
facilitate her own intuitive inference of their unverbalized attitudes. Unfortunately, for the most part, observations by psychoanalysts of client characteristics or attitudes which were based on postural variables remained informal. Thus, hypotheses which related postural variables to communicator attitudes or feelings remained mostly implicit in such work.

A general theory which would relate posture, orientation, and distance cues to either the communication of attitudes or status relationships is lacking. However, there are a few concepts which have occasionally been used to relate these nonverbal variables to attitudes. For example, Hall (1963) subsumed a number of the variables under his concept of proxemics. Some proxemic variables are distance between a communicator and his addressee, the degree of orientation of a communicator toward his addressee (i.e., the degree to which a communicator's body is turned in, versus away from, the direction of his addressee), and the presence or absence of touching or eye contact between communicator and addressee. Thus, the concept of proxemics subsumes variations in posture and distance variables which relate to the degree of directness or immediacy of interaction between a communicator and his addressee (Mehrabian, 1967; Wiener \& Mehrabian, 1968). In addition to eye contact and directness of body orientation, Machotka (1965) also denoted accessibility of a communicator's body to the addressee (such as openness of the arrangement of arms) as a relevant attitude- or affect-communicating variable. The latter can also be construed as a proxemic variable. Hall's (1963) interest in the introduction of the concept of proxemics seems to have been its function in the delineation of those aspects of posture and distance which are acceptable and represent implicit standards within a given social or subcultural group. The concept of immediacy proposed by Mehrabian (1967) and Wiener and Mehrabian (1968) was used primarily for the characterization of the role of these postural variables in the determination of attitudes between communicators. Greater immediacy or, in Hall's terms, greater proxemic relationships were hypothesized to cor- respond to more positive attitudes. However, very immediate postures or positions were hypothesized to lead to negative attitude inferences if the immediacy exceeded that allowed by the implicit social norms of a subculture.

The differential role of nonverbal cues in the communication of gross affect (e.g., attitude) versus specific affect (e.g., fear) has also been considered in broad terms. Ekman and Friesen (1967) presented a reformulation of Ekman's (1964) findings relating to the relative roles of bodily and facial cues in the communication of affect. They distinguished stationary positions from movements of body and face and suggested that movements are more likely to communicate specific emotions, whereas postures and stationary facial expressions are more likely to communicate gross affect. They also suggested that the intensity of specific emotions can be inferred from bodily or facial cues which are either stationary or moving. However, since facial movements are more frequent than bodily movements (i.e., changes in posture), it would follow that facial cues can be more informative about the intensity of emotions of a communicator than can his bodily cues. It, thus, seems useful to be able to delineate some of the significant variables of body position, rather than of body movements, for the inference of communicator attitude, since the former can serve as one basis for attitude inference when a communicator does not, or cannot, express his emotions in the more readily recognized verbal and facial channels.

Early studies are exemplified by Allport and Vernon's (1933) investigation of the relation of postural and gestural styles to personality characteristics and James' (1932) study dealing with the significance of posture as communicating feeling or attitude. Since the present paper deals mainly with attitude communication, the study by James seems to be one of the most directly relevant of the earlier investigations.

James (1932) used photographs of one masked male model as stimuli. He asked his subjects about the attitude being expressed by each posture and the portions of the posture which were most significant. 
He used 347 photographs in which the positions of head, trunk, feet, knees, and arms were systematically varied-certain combinations being eliminated due to their awkward quality. He selected 30 of these photographs on the basis of the highest agreement among his three $S s^{\prime}$ judgments of the attitude being communicated. Two additional experiments in which $S_{s}$ interpreted the set of 30 selected postures yielded the following four postural categories: (a) approach, an attentive posture communicated by a forward lean of the body; $(b)$ withdrawal, a negative, refusing, or repulsed posture communicated by drawing back or turning away; (c) expansion, a proud, conceited, arrogant, or disdainful posture communicated by an expanded chest, erect or backward-leaning trunk, erect head, and raised shoulders; (d) contraction, a depressed, downcast, or dejected posture communicated by a forward-leaning trunk, a bowed head, drooping shoulders, and a sunken chest. For each of these four generic categories, the head and trunk position(s) were found to be the most important indicators. However, specific discriminations within each category were determined by the position of hands and arms. In his third experiment, James (1932) found that postures were generally interpreted in the same way whether $S$ viewed the posture and interpreted it or whether $S$ viewed and imitated the posture and then interpreted it. Finally, James found that a decoder- $S$ 's response could be affected by the situation in which the posture occurred [Mehrabian, 1968a, pp. 296-297].

James' categories of approach and withdrawal relate to the backward lean of the torso and directness of orientation variables considered subsequently. As indicated previously, his findings suggest that a forward lean communicates a relatively positive attitude, whereas a backward lean or turning away communicates a more negative attitude. James' expansion category seems relevant to the communication of status differences, whereas his contraction category does not yield information about a communicator's attitude toward an addressee.

In considering the previous findings by James, and other findings reported subsequently, it is useful to distinguish between encoding and decoding methodologies in studies of communication. A decoding methodology is one in which the subjects of the experiment are presented with prepared stimuli, as in James' study, and are instructed to infer feelings and attitudes from the stimuli. In contrast, in an encoding methodology, the subjects are placed in experimental situations which elicit different kinds of attitudes from them, and the observations of their posture and positions are used to study the concomitants of the induced attitude. Typical encoding methodologies employ role playing, in which a subject is requested to assume a certain type of role or attitude toward his addressee (e.g., Rosenfeld, 1966). Occasionally there are studies which take advantage of existing likes and dislikes among subjects and studies which actually induce like or dislike in a subject toward the addressee (e.g., Exline \& Winters, 1965).

In the following sections, the attitude- and status-communicating significance of various cues are discussed separately. Before proceeding to a discussion of experimental findings relating to attitude and status communication, it is important to note that many of the variables to be considered can also serve other functions in communication, functions which the author does not deal with. For example, the work of Condon and Ogston (1966) has dealt with synchronous relations between verbal and nonverbal cues emitted by a communicator or between the communicator's verbal and addressee's nonverbal behaviors. One implication of their work is that there is a coactive regulation of communicator-addressee behaviors which is an intrinsic part of social interaction and which is certainly not exhausted through a consideration of the verbal portion of communications. The latter concept of regulation in communication has been the primary focus of the work of Scheflen $(1964,1965)$. According to Scheflen, changes in posture, eye contact, or position may be employed by a communicator to indicate that $(a)$ he is about to make a new point, $(b)$ he is taking an attitude relative to several points being made by himself or by his addressee, and $(c)$ he is temporarily removing himself from the communication situation, as would be the case if he were to select a large distance from the addressee or to orient so that his back were facing the addressee. There are many interesting aspects of the regulative function of nonverbal cues which have heretofore been dealt with only in some informal descriptions of interpersonal interactions. 


\section{Distance}

In his informal discussion of the significance of distance between communicators, Hall $(1959,1963)$ noted the presence of implicit norms within any culture or subculture regarding the permissible ranges of distance between two speakers. If the distance between two speakers exceeds or is less than the limits which are implicitly allowed, then negative attitudes are elicited or inferred. Hall (1964) noted that in the United States, distances of from 6 to 18 inches are typical for intimate interpersonal situations, distances of from 30 to 48 inches are typical of casualpersonal interaction, distances of from 7 to 12 feet are characteristic of social-consultative situations, and distances of 30 feet and more are characteristic of public interaction situations.

One implication of the norms provided by Hall is that if a communicator exceeds the distance which is appropriate to a given social situation or tries to maintain a smaller distance than is appropriate, then a negative attitude can be inferred by his addressee. Hall (1959) provided several examples of interactions among communicators from different cultures whose implicitly acquired norms for such distances were different and thus led to misunderstandings about attitudes. Studies by Garfinkel (1964) and Felipe and Sommer (1966) support Hall's observations. Garfinkel (1964) found that the violation of the implicit norms regarding allowable distances led to the bewilderment and embarrassment of an addressee and to his subsequent avoidance of the communicator. Again, Felipe and Sommer (1966) found that when a communicator assumed an inappropriately close position to another person, that person left earlier than he otherwise would have.

For those variations in distance which occur within the culturally acceptable limits, a number of experimental studies have yielded systematic findings relating the distance to the attitude between a communicator and his addressee. Sommer (1967) reviewed some of the studies relating attitudes of communicators to distances which they maintain vis-àvis their addressees. Leipold (1963) used an encoding method in which subjects were interviewed by an experimenter who they expected would evaluate them positively or negatively, based on information provided to the subjects by a confederate of the experimenter prior to the interview. Subjects who expected a negative evaluation selected chairs which were farther away from the experimenter during the interview than did subjects who expected a positive evaluation. Also, Little (1965) used line drawings, silhouettes, and live actresses in experiments in which the subject selected (encoded) appropriate distances between them to convey attitudes. He found that smaller distances were selected by subjects for closer relationships between communicators.

Rosenfeld (1965) instructed his subjects to role play (encode) an approval-seeking in contrast to an approval-avoiding attitude toward another "subject" (a confederate in the experiment). Rosenfeld found that under the approval-seeking instructions, subjects sat closer to the confederate than they did under the approval-avoiding instructions.

When Golding (1967) used semantic differential ratings of line drawings involving human figures, he found that closer distances were interpreted (decoded) as being accepting and responsive, whereas greater distances between communicators were interpreted in opposite terms.

Mehrabian (1968a) used both encoding and decoding methods to investigate the relation of distance to attitude. In his decoding method, subjects were requested to infer the degree to which another person liked or disliked them on the basis of the distance that he stood from them. In the encoding method, subjects were required to imagine liked versus disliked addressees and to assume a standing position characteristic of their interactions with such people. He found that when a communicator stood close (i.e., 3, as opposed to 7 , feet) to his addressee, a more positive attitude was both inferred and communicated. Mehrabian (1968b) also used an encoding method in which the subject was required to role play five degrees of attitude toward the addressee. It was found that distance linearly decreased as positive attitude toward the addressee increased. 
Although Hall $(1959,1966)$ informally discussed possible systematic differences in the distances which communicators in different national groups assume vis-à-vis each other, experimental studies of the problem have been lacking. A recent study by Little (1968) requested subjects of various national groups to position dolls relative to one another for a variety of social situations. His findings indicate that, on the average, over the different social situations, Greeks, Americans, Italians, Swedes, and Scots, in that order, assigned increasing distances between communicators. He also investigated the effects of affect and familiarity on the distances at which the dolls were placed from each other. $\mathrm{He}$ found that "friends are seen as interacting closer together than acquaintances, and acquaintances closer than strangers. In regard to affect, however, although pleasant topics clearly produced the closest placement of the figures, the neutral and unpleasant topic situations were not significantly different . . . [Little, 1968, p. 5]." Although Little's data provided a basis for assessing the effect on distance of status differences, his analyses of the data do not yield such information. He did indicate, however, that "women see interactions of women with authority figures or superiors taking place at a greater distance than men view sirnilar transactions of male figures [1968, p. 5]."

In sum, then, the findings from a large number of studies corroborate one another and indicate that communicator-addressee distance is correlated with the degree of negative attitude communicated to and inferred by the addressee. In addition, studies carried out by sociologists and anthropologists indicate that distances which are too close, that is, inappropriate for a given interpersonal situation, can elicit negative attitudes when the communicator-addressee relationship is not an intimate personal one.

Lott and Sommer (1967) found that people of equal status sat closer than people of unequal status. Mehrabian (1968a) used an encoding method with seated subjects and did not find any relationship between the status of a communicator relative to his addressee and the distance of the former to the latter. The latter finding is not inconsistent with the findings of the Lott and Sommer (1967) study, however, because the experimental conditions which were explored in Mehrabian's (1968a) study always involved an unequal status between the communicators (i.e., the addressee was either of a higher or a lower status than the communicator, or the discrepancy in status was the same in all conditions), and the studies yielded no significant difference in the distance that a communicator placed himself from a higher status addressee compared to a lower status addressee. The evidence from the two studies therefore suggests that the distance between two communicators is positively correlated with their status discrepancy.

Sommer's (1967) review of status relationships and spatial arrangements suggested that perhaps the body orientation of communicators, rather than the distances between them, is a more important variable for the communication of status relationships. Findings relating orientation are reviewed subsequently in a separate section.

\section{Eye Contact}

Hall (1963) included eye contact, along with distance, as another index of proxemics. In other words, he conceptualized that the degree of eye contact of a communicator with his addressee could also serve as an index of the attitude of the communicator toward the addressee. Kendon (1967) provided a review of part of the literature dealing with the significance of eye contact in the communication of attitudes. He distinguished between two major functions served by eye contact-the regulatory function and the expressive function. Thus, for example, eye contact is regarded as regulating the initiation and termination of verbal interchanges. (Incidentally the same function may be associated with the remaining posture and position variables which are considered in the present review, for example, Scheflen, 1964, 1965.) However, the more interesting aspect of eye contact in the present paper is its expressive function, that is, the attitude-communicating significance of varying degrees of eye contact between communicators.

Reece and Whitman (1962) studied the effect of an investigator's warmth and cold- 
ness upon the amount of verbal output in a situation where the subject was free associating. They defined warmth in terms of more frequent smiling, the absence of finger-tapping movements, greater degree of eye contact with the subject, and greater degree of forward bodily lean (in a chair) toward the subject. They found that the nonverbal variables assumed to indicate experimenter warmth or positive attitude toward the subject did significantly affect the total number of words produced by the subject, that is, more words were produced by the subject when the experimenter nonverbally indicated a more positive attitude. The findings by Reece and Whitman do not permit an assessment of the individual roles played by more forward bodily lean, more frequent smiling, greater eye contact, or the lack of nervous hand movements in the attributing of warmth to the experimenter. The following experiments, however, do indicate that eye contact is an indicator of variations in attitude toward an addressee.

Studies by Exline and his colleagues (e.g., Exline, 1963; Exline \& Eldridge, 1967; Exline, Gray, \& Schuette, 1965; Exline \& Winter, 1965) or Nachshon and Wapner (1967) can be interpreted as indicating that a higher percentage of eye contact between communicators is typically associated with more positive attitudes between the communicators. Exline et al. (1965) found that female subjects, who tend to be more affiliative than male subjects, have more eye contact with an experimenter than do male subjects. Furthermore, they found that when the experimenter questioned the subjects about potentially embarrassing contents, eye contact was less than when he questioned them about innocuous contents. Both sets of findings can be interpreted to indicate that greater degrees of eye contact are associated with more positive attitudes toward the interviewer. In the case of the difference between the eye contact of males and females, the attitudes of females, who are more affiliative, can be assumed to be more positive toward people in general or to the interviewer in particular. In the case of the effects due to topic, the experimenter who asked relatively innocuous questions can be considered to be more positively received than the one who asked personal and possibly embarrassing questions.

Exline and Winters (1965) reported that subjects avoided the eyes of an interviewer, and disliked him, after he had commented unfavorably about their performance. Again, Exline and Eldridge (1967) used a decoding method and found that the same verbal communication was decoded as being more favorable by a subject when it was associated with more eye contact than when it was presented along with less eye contact.

Argyle and Dean (1965) found that for a given degree of communicator attitude toward an addressee, the degree of eye contact decreased as closeness increased. Fischer (1968) reported similar findings: "When three profiles are freely placed, the metric distance between figures facing each other is larger than the distance to the third figure, thus compensating for the latter's lesser perceived social closeness by greater metric closeness [p. 13]." The latter findings suggest that both eye contact and closeness additively reflect degree of communicator attitude toward or intimacy with the addressee, and therefore that increases (or decreases) in the former are associated with compensatory decreases (or increases) in the latter when the attitude is constant.

For communicators who were standing, Mehrabian (1968a) found that whereas males had significantly more eye contact with liked addressees than with disliked addressees, females did not. Mehrabian and Friar's (1969) study indicated that in a sitting position, male communicators, irrespective of the addressee sex, had less eye contact with disliked addressees than with liked addressees; further, female communicators had significantly less eye contact with disliked male addressees than with any of the other three addressee groups, that is, liked males, liked females, and disliked females. Mehrabian (1968b) investigated the eye contact of seated communicators as a function of five degrees of communicator attitude toward the addressee. $\mathrm{He}$ found that the amount of eye contact with an addressee was a parabolic function of attitude toward that addressee, such that eye contact was minimal for a disliked addressee, approached a maximum value for addressees 
toward whom the attitude was neutral, and slightly diminished for addressees who were liked very much. Thus, as in the case of the studies of Argyle and Dean (1965) or Fischer (1968), compensatory decreases in eye contact were obtained when communicators assumed small distances to addressees who were liked very much.

In sum, findings which relate degree of eye contact to attitudes in nonthreatening interpersonal situations suggest that males show greater variability in their eye contact with their addressees relative to females and that they more consistently exhibit greater degrees of eye contact with liked than disliked addressees. Further, experimental studies provide consistent support for the assumed correspondence of the decoded significance of eye contact by an addressee and that encoded by a communicator.

It is interesting to extrapolate the hypothesis which relates degree of eye contact to attitudes to obtain a hypothesis for the visual behavior of approval-seeking or dependent individuals relative to that of more independent or dominant persons. To a dependent or approval-seeking individual, others are almost by definition more important sources of gratification (i.e., reinforcers) than to an independent person. Thus, a dependent person would be expected to communicate more positive attitudes nonverbally, as with relatively higher levels of eye contact. In support of the latter, Efran and Broughton (1966) reported a significant correlation between scores on the Crowne and Marlowe (1960) social desirability scale and the extent of eye contact the subjects had with their addressees. However, in a subsequent study, Efran (1968) failed to replicate that finding. Additional findings by Exline and Messick (1967) suggest that eye contact may be used by dependent individuals not only to communicate more positive attitudes, but also to elicit such attitudes when they are not forthcoming: They found that dependent males had more eye contact with a listener who provided them with few as compared to many social reinforcers, whereas dominant males decreased their eye contact with less reinforcing listeners.

Studies have also indicated that eye con- tact is significantly related to the status relationship between communicators. Sommer (1967) reviewed some of the literature dealing with the spatial arrangement of subordinates and leaders. For example, findings by Hearn (1957) imply that eye contact with an addressee is a parabolic function of the status of that addressee, provided distance and other variables are held constant. Thus, eye contact is moderate with a very high-status addressee, at a maximum with a moderately high-status addressee, and at a minimum with a very low-status addressee.

There is some available evidence relevant to that part of the previous interpretation of Hearn's (1957) findings which deals with moderately high-status versus low-status addressees. Efran (1968) investigated the eye contact of freshmen with seniors and freshmen who were the addressees. The results indicated that, of a senior-freshman pair who were simultaneously being addressed by a freshman, the senior received more eye contact from the subject than did the lower status freshman.

Among standing communicators, Mehrabian (1968a) found that both males and females had significantly more eye contact with high-status addressees than with lowstatus addressees. The difference, however, was greater for male than for female communicators. Mehrabian and Friar (1969) found that, regardless of a seated communicator's sex, there was significantly less eye contact with low-status male addressees than with any of the other three addressee groups, that is, low-status females, high-status males, and high-status females. In addition, the status and attitude factors interacted in determining degree of eye contact of a seated communicator with the addressee. For male communicators, there was more eye contact with liked high-status addressees than with disliked high-status, liked low-status, or disliked low-status addressees-the latter three means not differing significantly among themselves. For female communicators, however, the significant difference was less eye contact with disliked low-status addressees than with disliked high-status, liked high-status, or liked low-status addressees-the latter three means not differing significantly among them- 
selves. In other words, for seated male communicators, it was the liked high-status addressees who elicited a discriminably greater degree of eye contact, whereas for seated female communicators, it was the disliked lowstatus addressees who elicited a discriminably smaller degree of eye contact.

Finally, as in the case of cross-cultural studies of distance, studies of eye contact and other posture and position cues could yield consistent differences in, for instance, national groups varying in the degree to which they are socially stratified. It may be hypothesized that variations in eye contact as a function of variations in status of an addressee may be more clearly defined in the more authoritarian than the more democratically oriented cultures. In addition to eye contact, the various cues of body relaxation, such as asymmetry of limb placement or sideways and reclining angles of seated communicators, may also exhibit less ambiguous relationships as a function of the status of the addressee in authoritarian than in democratically oriented cultures.

\section{Body Orientation}

Body orientation (i.e., the degree to which a communicator's shoulders and legs are turned in the direction of, rather than away from, his addressee) can also serve as an indicator of communicator attitude or status. However, investigations which have employed body orientation as a dependent measure have yielded findings which are not as unambiguous as those obtained in relation to distance or eye contact (e.g., Argyle \& Kendon, 1967). For example, Rosenfeld (1965) did not find a significant difference in the body orientation of his subjects toward the addressee in an approval-seeking, in contrast to an approval-avoiding, situation.

It should be noted that, in a number of studies where body orientation has been a variable of interest, the effects of body orientation and eye contact have been confounded. Greater degrees of eye contact with an addressee tend to be associated with a more direct orientation of the head, shoulders, and legs of a communicator toward his addressee. For example, Mehrabian (1968a), using an encoding method, found that for communi- cators who are in a standing position, shoulder orientation (i.e., the number of degrees that a plane perpendicular to the plane of the subject's shoulders is turned away from the median plane of his addressee) correlated -.41 with eye contact. In other words, in a standing position, the greater the directness of orientation toward the addressee, the greater was the eye contact with the addressee. Mehrabian (1968b) used indices of head, shoulder, and leg orientation, in addition to the eye contact measure, based on encoded communications of seated subjects. Average figures from the latter and the Mehrabian and Friar (1969) study indicated intercorrelations among the head, shoulder, and leg orientation measures in excess of .80 . Furthermore, eye contact correlated -.51 with head orientation; -.40 with shoulder orientation; and -.34 with leg orientation. The data relating the various orientation measures to each other and to eye contact for seated and standing communicators indicate that there is considerable consistency among the various orientation measures. Therefore, shoulder orientation alone can be used as a summary index of the body orientation of standing or seated communicators. Furthermore, the correlations of eye contact with the various orientation indices are low enough that body orientation and eye contact can be treated as separate indices of attitude and status.

In the following experiment by Mehrabian (1967) the effects of eye contact and body orientation were experimentally separated. The experimenter, while presenting a brief talk to her subjects about a topic which was not related to attitude communication, systematically varied her posture vis-à-vis the two subjects who were simultaneously present. For half of the pairs of subjects, the experimenter had eye contact and direct body (i.e., shoulder and leg) orientation $90 \%$ of the time with one subject in the pair and had eye contact and direct body orientation $10 \%$ of the time with the other subject in the pair. For the other half of the paired subjects, one of each pair received $90 \%$ eye contact and $10 \%$ body orientation, whereas the other subject in the pair received $10 \%$ eye contact and $90 \%$ body orientation. Thus, the effects 
of eye contact and body orientation were separated in the design, and the female subjects' judgments (decodings) of how much they thought the experimenter liked them served as the dependent measure. More eye contact communicatd a more positive attitude. Further, when eye contact was present, less direct body orientation of the communicator was interpreted as an indicator of less positive attitude than when there was more direct body orientation. This effect due to body orientation was not found when there was an absence of eye contact.

Mehrabian (1968a) did not find any significant relationship between the body orientation of standing communicators and their encoded attitudes toward their addressees. However, in the case of seated communicators, Mehrabian (1968b) found the following relationships between shoulder orientation and increasing degrees of positive communicator attitude (corresponding to intense dislike, moderate dislike, neutral, moderate liking, and intense liking). Shoulder orientation was not a discriminator of varying degrees of male communicator attitude except when the addressee was liked very much, in which case the shoulder orientation was less direct. The shoulder orientation of female communicators functioned in a similar manner to their eye contact: It was a parabolic function of increasing degrees of attitude and was most direct for neutral addressees, least direct for intensely disliked addressees, and moderately direct for intensely liked addressees.

Shoulder orientation of a communicator toward the addressee has also been found to be related to the relative status of a communicator to the addressee. For communicators in a standing position, Mehrabian (1968a) found that shoulder orientation was more direct with a high-status than with a low-status addressee, regardless of the attitude toward the addressee.

Additional decoding experiments in which the effects of body orientation and eye contact can be separated are required to clarify the relationships of directness of shoulder orientation to attitudes and status relationships. The evidence which is presently available suggests that males use a less direct body orientation when the addressee is liked very much and that females use very indirect body orientation with intensely disliked addressees, least indirect orientation with neutral addressees, and moderately indirect orientation with liked addressees. The latter findings are for communicators who are seated. For standing communicators, body orientation has not been found to be different when the addressee is extremely liked versus extremely disliked. Finally, body orientation is more direct to a higher status than to a lower status addressee.

\section{Accessibility of Body-Openness of Arms} and Legs

Machotka's (1965) observations suggested that subjects were more drawn to a nude figure in a moderately open-armed position than to figures which had a very open or a closed-arm position. The subjects in the study rated line drawings displaying different degrees of the openness of arm arrangement of nude female figures. Compared to the figures with moderate or very open arm positions, the figures with closed-arm positions were judged as being cold, rejecting, shy, and passive. Thus, Machotka's study suggested that more accessible communicator postures communicated more positive attitudes toward the addressee. Mehrabian (1968a) used two indices of the accessibility of a communicator's body, namely, the degree of openness of the arrangement of the arms and legs. No significant correlation between the openness of the arrangement of arms and legs of the standing communicators was obtained. Furthermore, the male communicators did not assume a more open arm or leg position with the liked than disliked addressees. However, females assumed a more open arrangement of the arms while communicating to liked male than to disliked male addressees; there was no corresponding difference when the addressees were female. In a study in which five degrees of communicator attitude were explored, Mehrabian (1968b) found no significant relationship between openness of the arrangement of arms or legs of seated communicators and their attitude toward the addressees.

In an experiment in which subjects inferred (decoded) the attitude of a seated communicator, accessibility of posture was found to 
relate to inferred attitudes. Mehrabian (1968a) found that whereas an open posture of male encoders did not communicate a more positive attitude than a closed posture, an open posture of female encoders sometimes did. For the open posture, encoders were asked to sit with their arms resting on their laps with hands not touching and both feet resting on the floor in a normal legs-uncrossed position. For the closed posture, they were asked to sit with their arms folded and their legs crossed. The communicators were moderately relaxed in both postural positions. In two experiments, relative to the decoder, the communicators were either discriminably older and more formally dressed, or of the same age, or in the age range from 10 to 13 . For a relaxed posture, which is more typical of everyday communication situations, a more accessible posture of males was not decoded by males or females as being a significant determiner of attitude, whereas a relatively accessible posture of females (younger or older but not of the same age as the decoder) was decoded as communicating a more positive attitude.

Whereas the body accessibility of a communicator does not seem to be a consistent correlate of the communicator's attitude toward the addressee, some findings suggest that it is systematically related to status relative to the addressee. Standing female communicators assumed more open arm positions in the presence of higher status addressees, whereas there was no similar difference in the case of male communicators (Mehrabian, 1968a). In Mehrabian and Friar's (1969) study, seated female communicators who were addressing a high-status addressee assumed a significantly less open arm position than female communicators who were addressing a low-status addressee. Thus, only in the case of female communicators has an open arm position been found to indicate status relationships. While the person was standing greater degrees of openness of arm position (i.e., arms tending to be hanging rather than crossing in front of the chest) occurred with a high-status addressee, whereas while the person was seated less arm openness occurred with a high-status addressee than with a lowstatus addressee.
Recent data, discussed in the following section, together with the preceding relationships of the openness of arm arrangement and status of an addressee suggests that an open arm position of seated communicators may more appropriately be considered an index of relaxation, with relatively more open positions indicating greater relaxation. In contrast, for standing communicators, a folded arm position may be more relaxed than one with the arms hanging. Given these considerations, then, the experimental data need to be reexamined in terms of the degree of relaxation which can be inferred from arm or leg arrangement, rather than the accessibility they provide to the body. Thus, for instance, although the folded arm position of seated females may be a more "proper" and tense position, that same closed arm position while standing may be considered a more relaxed position and may thus occur more with lower status addressees.

\section{Arms-Akimbo Position}

Mehrabian (1968a) found that the use of the arms-akimbo position by a standing communicator was indicative both of the attitude and the status of the communicator relative to his addressee. Specifically, he found that there was a greater tendency for a communicator to use the arms-akimbo position with disliked addressees than with liked addressees. Furthermore, there was a greater tendency to use an arms-akimbo position with low-status than with high-status addressees.

\section{Relaxation Measures}

Schlosberg (1954) denoted the dimension of sleep-tension as being relevant to the expression of emotions. Dittmann, Parloff, and Boomer (1965), in selecting stimuli for an experiment in which they were concerned with the pleasantness of bodily and facial cues, indicated that it was more difficult to characterize the pleasantness of bodily than of facial cues. However, in selecting pleasant body positions they looked for relaxed postures with little movements, while in selecting unpleasant body positions they looked for those involving obvious muscle tension or fidgety and nervous activity. In their study, which was a decoding one, they found that 
dancers were more attuned to bodily cues than psychotherapists who attempted to make most of their judgments on the basis of facial pleasantness. However, the investigators noted that both the psychotherapists and the dancers were influenced more by the facial than by the bodily cues in making their judgments of pleasantness and unpleasantness.

In a number of studies, separate indices of the degree of relaxation of a communicator's hands, legs, and trunk have been obtained. It will be recalled that Reece and Whitman (1962) assumed that a warm experimenter attitude was communicated to the subject if the experimenter leaned forward in his chair, smiled, kept his hands still, and had more eye contact with the subject. However, as has already been noted, their findings did not clearly indicate which of these postural and facial variables influenced the number of words produced by a subject who was free associating. A number of recent findings indicate that a smaller reclining angle of a communicator while seated, and therefore a smaller degree of trunk relaxation, communicates a more positive attitude. For example, Mehrabian (1968a) found that both male and female addressees inferred a more negative attitude when the communicator was leaning backward and away from them than when he was in a forward leaning position. Further, Mehrabian (1968b) found that in attempting to communicate variations in attitude, communicators' reclining angles with disliked or neutral addressees were not significantly different, but that the angles decreased for increasing positive attitudes toward the addressees. Finally Gottheil, Corey, and Paredes (1968) reported a significant correlation between the reclining angle which a person assumed while talking to an interviewer and the distances which he used to represent his typical distances with significant others in social situations. That is to say, persons who tended to communicate less positive feelings by reclining more also tended to perceive themselves as assuming greater distances from addressees in general.

In addition to reclining angle, a second index of trunk relaxation is the degree of sideways lean of a seated communicator. Meh- rabian's (1968b) study which related the degree of sideways lean to attitude toward the addressee yielded different results for male and female communicators. Male communicators exhibited less sideways lean and generally less body relaxation with intensely disliked males, whereas females exhibited their largest degree of sideways lean with intensely disliked male or female addressees. For the remaining four degrees of attitude, the sideways-lean index of relaxation exhibited similar patterns for male and female communicators. Thus, sideways lean was moderately high for disliked addressees, was lowest for neutral addressees, and was moderately high for liked and intensely liked addressees.

In contrast to indices of body relaxation, those relating to arm and leg relaxation have failed to yield consistent relationships with attitude (e.g., Mehrabian, 1968b). Earlier studies employed rather global judgments of the degree of relaxation in the arms or legs of communicators. In several of the author's recent unpublished experiments, the degree of asymmetry in the arrangements of the arms and legs was employed as a possible measure of relaxation in the limbs. Factoranalytic results from such experiments suggested that the following postural and movement variables define relaxation: sideways lean while seated, reclining angle, leg-position and arm-position asymmetry, arm openness, and higher rates of gesticulation and rocking and lower rates of lateral swivel while seated on a desk chair. Thus, the heretofore neglected variables of symmetry in the arrangement of arms and legs, which have been found to be valid indices of relaxation-tension, seem promising variables for exploring attitudes and status relations between communicators.

The findings relating to relaxation can be summarized by noting that there is a curvilinear relationship between the attitude of a communicator toward his addressee and the degree of relaxation manifested by the communicator. Degree of relaxation is either very high or very low for a disliked addressee and is moderate for a liked addressee [Mehrabian \& Friar, 1969].

Further, the obtained sex differences provide information regarding the preferred modes of 
expressing dislike through variations in relaxation on the part of males and females.

It seems that a very disliked male addressee who could be threatening to another male elicits a relatively tense posture from that communicator, whereas a disliked female addressee elicits an extremely relaxed posture from a male communicator. Female communicators, on the other hand, do not exhibit differences in their body relaxation with male and female addresses and in both instances communicate dislike with greater degrees of relaxation.

The findings relating to sideways lean and shoulder orientation suggest a consistent pattern of differences for the nonverbal behaviors of male and female communicators vis-à-vis male addressees who are disliked intensely. Relative to females, male communicators exhibit less body relaxation (as indicated by less sideways lean) and a greater degree of vigilance (as indicated by more direct shoulder orientation and a similar trend approaching significance for eye contact) toward intensely disliked males. Otherwise, for the remaining four degrees of attitude, the communication behaviors of males and females exhibit similar patterns. The differences obtained for intensely disliked male addressees can be interpreted by suggesting that these addressees are potentially a greater physical threat to a male than a female communicator and therefore elicit a greater degree of body tension and vigilance from the former than from the latter [Mehrabian, 1968b, p. 29].

In connection with the latter discussion of the significance of vigilance which is exhibited by less sideways lean, more direct shoulder orientation, and more eye contact, it is interesting to note the following findings by Ellsworth and Carlsmith (1968): "If the topic of conversation is neutral to generally positive, subjects like the interviewer significantly more when she looks them in the eye. ... But in a conversation which is indirectly but persistently critical of the subject, this relationship is reversed [p. 18]." The findings from the two latter studies indicate that a threatening person elicits more vigilance and eye contact and that threatening comments, when associated with more eye contact, are more offensive. In short, in the context of a hostile relationship, higher levels of eye contact are elicited and communicate more negative feelings.

There are additional findings which relate various indices of relaxation and communicator-addressee relative status. Goffman (1961) noted that in psychiatric staff meetings, lower status participants (interns) were less relaxed than the higher status participants (psychiatrists). Findings obtained from communicators who were in a standing position corroborated some of the observations by Goffman. Mehrabian (1968a) found that hand as well as leg relaxation was greater while communicating to a lower status addressee. Further, Mehrabian and Friar (1969) found that communicators exhibited more sideways lean with low-status than with highstatus addressees.

In sum, then, in contrast to its relationship to attitude, relaxation seems to exhibit a linear relationship with status, as follows: There is a high degree of relaxation with a low-status addressee, a moderate degree of relaxation with a high-status addressee, and an intermediate degree of relaxation with peers.

\section{SUMMARY}

An overview of the findings which relate the posture of a communicator to his attitude toward his addressee suggest the following consistent patterns. The distance between a communicator and his addressee is a decreasing linear function of the degree of liking of the addressee. Eye contact is minimal for disliked addressees, approaches a maximum value for addressees toward whom the attitude is neutral, and slightly diminishes for addressees who are liked very much. For female communicators, body orientation toward the addressee, like their eye contact, is a parabolic function of attitude toward the addressee, such that the least direct orientation occurs for intensely disliked addressees, the highest degree occurs for addressees who are regarded as neutral, and, again, a relatively high degree occurs for addressees who are liked very much. For male communicators, the only significant difference occurs with intensely liked addressees, who receive a less direct body orientation. The slight decrease in the directness of orientation of males or females toward intensely liked addressees may be understood in terms of the tendency of communicators to assume a side-by-side and very close position when they communicate to such addressees.

Several variables relating to the positioning of the arms and legs of a communicator have been explored. These include degree of asymmetry, and openness of the arrangement 
of arms and legs, as well as uses of the armsakimbo position. An open arrangement of the arms of seated females has been found to communicate a more positive attitude to older or younger addressees, but not to addressees of the same age. An arms-akimbo position tends to be used by communicators who wish to indicate a more negative feeling to their addressees. There are no studies of the relation between an asymmetrical arrangement of the arms or legs and attitudes, however, these have been found to be indices of communicator relaxation. Two additional indices of relaxation, reclining and sideways-leaning angles while seated, have yielded significant relations with attitude. A larger reclining angle communicates a more negative attitude, and whereas moderate values of sideways lean convey positive attitudes, very large or small reclining angles communicate neutral or negative attitudes.

Findings which relate the posture and position of a communicator to his status relative to his addressee suggest the following consistent pattern. The distance between two communicators is positively correlated with their status discrepancy. General considerations suggest that eye contact is moderate with high-status, is at a maximum with moderately high-status, and is at a minimum with low-status addressees, with some supporting evidence which deals with moderately highstatus- versus low-status-addressee communication situations. Further studies require designs which allow the assessment of the separate effects of body orientation and eye contact in relation to status difference between communicators.

The use of an arms-akimbo position is less probable when the addressee is of a higher status. Relationships between indices of relaxation of hands, legs, and trunk and the status of an addressee indicate that when the communicator is in a standing position, hand as well as leg relaxation is greater while communicating to a low-status than to a highstatus addressee. When the communicator is in a seated position, the sideways-lean index of trunk relaxation has been found to be greater with low-status than with high-status addressees.

\section{REFERENCES}

Allport, G., \& Vernon, P. Studies in expressive movement. New York: MacMillan, 1933.

Argyle, M., \& Dear, J. Eye contact, distance and affiliation. Sociometry, 1965, 28, 289-304.

Argyle, M., \& Kendon, A. The experimental analysis of social performance. In L. Berkowitz (Ed.), Advances in experimental social psychology. New York: Academic Press, 1967.

Beakel, N. G., \& Merrabian, A. Inconsistent communications and psychopathology. Journal of $A b$ -

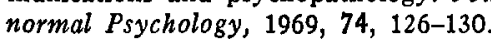

Braatoy, T. F. Fundamentals of psychoanalytic technique. New York: Wiley, 1954.

Condon, W. S., \& Ogston, W. D. Sound film analysis of normal and pathological behavior patterns. Journal of Nervous and Mental Disease, 1966 , 143, 338-347.

Crowne, D. P., \& Marrowe, D. A new scale of social desirability independent of psychopathology. Journal of Consulting Psychology, 1960, 24, 349354.

Deutsch, F. Analysis of postural behavior. Psychoanalytic Quatterly, 1947, 16, 195-213.

Deutsch, F. Analytic posturology. Psychoanalytic Quarterly, 1952, 21, 196-214.

DeUtsch, F., \& MuRPhy, W. F. The clinical interview. New York: International University Press, 1955. 2 vols.

Ditrmann, A. T., Parloff, M. X., \& Boomer, D. S. Facial and bodily expression: $A$ study of receptivity of emotional cues. Psychiatry, 1965, 28, 239-244.

EFraN, J. S. Looking for approval: Effects on visual behavior of approbation from persons differing in importance. Journal of Personality and Social Psychology, 1968, 10, 21-25.

Efran, J. S., \& Broughton, A. Effect of expectancies for social approval on visual behavior. Journal of Personality and Social Psychology, 1966, 4, 103-107.

Ekman, P. Body position, facial expression and verbal behavior during interviews. Journal of $A b$ normal and Social Psychology, 1964, 68, 295-301.

Ekmax, P., \& Friesen, W. V. Head and body cues in the judgment of emotions: A reformulation. Perceptual and Motor Skills, 1967, 24, 711-724.

Errsworth, P. C., \& Carismith, J. M. Effects of eye contact and verbal content on affective response to a dyadic interaction. Journal of Personality and Social Psychology, 1968, 10, 15-20.

ExLINE, R. V. Explorations in the process of person perception: Visual interaction in relation to competition, sex, and need for affiliation. Journal of Personality, 1963, 31, 1-20.

Exline, R. V., \& Eldridge, C. Effects of two patterns of a speaker's visual behavior upon the perception of the authenticity of his verbal message. Paper presented at the meeting of the Eastern Psychological Association, Boston, April 1967.

Exrine, R. V., Gray, D., \& Schuette, D. Visual behavior in a dyad as affected by interview con- 
tent and sex of respondent. Journal of Personality and Social Psychology, 1965, 1, 201-209.

ExIINE, R. V., \& MEssick, D. The effects of dependency and social reinforcement upon visual behavior during an interview. British Journal of Social and Clinical Psychology, 1967, 6, 256-266.

Exline, R. V., \& Winters, L. C. Affective relations and mutual glances in dyads. In S. Tomkins \& C. Izzard (Eds.), Affect, cognition and personality. New York: Springer, 1965.

Fritpe, N. J., \& Sommer, R. Invasions of personal space. Social Problems, 1966, 14, 206-214.

FIscher, C. T. Social schemas: Response sets or perceptual meanings? Journal of Personality and Social Psychology, 1968, 10, 8-14.

Fromm-ReIchmann, F. Psychoanalysis and psychotherapy. Chicago: University of Chicago Press, 1950.

GARFINKEL, H. Studies of the routine grounds of everyday activities. Social Problems, 1964, 11, 225-250.

GoFrmaN, E. Encounters. Indianapolis: Bobbs-Merrill, 1961.

GoldInG, P. Role of distance and posture in the evaluation of interactions. Proceedings of the $75 \mathrm{th}$ Annual Convention of the American Psychological Association, 1967, 2, 243-244.

Gotrheir, E., Corey, J., \& Paredes, A. Psychological and physical dimensions of personal space. Journal of Psychology, 1968, 69, 7-9.

HaLL, E. T. The silent language. New York: Fawcett, 1959.

HaLL, E. T. A system for the notation of proxemic behavior. American Anthropologist, 1963, 65, 1003-1026.

HaLL, E. T. Silent assumptions in social communication. Disorders of Communication, 1964, 42, 4155 .

Hall, E. T. The hidden dimension. New York: Doubleday, 1966.

HEARN, G. Leadership and the spatial factor in small groups. Journal of Abnormal and Social Psychology, 1957, 54, 269-272.

JAMES, W. T. A study of the expression of bodily posture. Journal of General Psychology, 1932, 7, 405-437.

KENDON, A. Some functions of gaze-direction in social interaction. Acta Psychologica, 1967, 26, 2263.

LEIPOLD, W. D. Psychological distance in a dyadic interview. Unpublished doctoral dissertation, University of North Dakota, 1963.

Lrrrue, K. B. Personal space. Journal of Experimental Social Psychology, 1965, 1, 237-247.

LITTLE, K. B. Cultural variations in social schemata. Journal of Personality and Social Psychology, $1968,10,1-7$.
Lotr, D. F., \& Sommer, R. Seating arrangements and status. Journal of Personality and Social Psychology, 1967, 7, 90-95.

Lowes, A. Physical dynamics of character structure: Body form and movement in analytical therapy. New York: Grune \& Stratton, 1958.

Machotka, P. Body movement as communication. Dialogues: Behavioral Science Research, 1965, 2, 33-65.

Mehrabian, A. Orientation behaviors and nonverbal attitude communication. Journal of Communication, 1967, 17, 324-332.

Mehrabian, A. Inference of attitude from the posture, orientation, and distance of a communicator. Journal of Consulting and Clinical Psychology, 1968, 32, 296-308. (a)

Menrabian, A. Relationship of attitude to seated posture, orientation, and distance. Journal of Personality and Social Psychology, 1968, 10, 26-30. (b)

Memrabian, A., \& Friar, J. T. Encoding of attitude by a seated communicator via posture and position cues. Journal of Consulting and Clinical Psychology, 1969, 33, in press.

NACHSON, I., \& WAPNER, S. Effect of eye contact and physiognomy on perceived location of other person. Journal of Personality and Social Psychology, 1967, 7, 82-89.

Reece, M. M., \& Whitman, R. N. Expressive movements, warmth and verbal reinforcement. Journal of Abnormal and Social Psychology, 1962, 64, 234-236.

ReIcH, W. Character analysis. (Trans. by T. P. Wolfe) New York: Orgone Institute Press, 1945.

RosenFeLd, H. M. Effect of an approval-seeking induction on interpersonal proximity. Psychological Reports, 1965, 17, 120-122.

Rosenfeld, H. M. Approval-seeking and approvalinducing functions of verbal and nonverbal responses in a dyad. Journal of Personality and Social Psychology, 1966, 4, 597-605.

SCHEFLEN, A. E. The significance of posture in communication systems. Psychiatry, 1964, 27, 316-331.

Scherten, A. E. Stream and structure of communicational behavior. Eastern Pennsylvania Psychiatric Institute, Behavioral Studies Monograph No. 1, 1965.

Schlosbero, H. Three dimensions of emotion. Psychological Review, 1954, 61, 81-88.

SOMMER, R. Small group ecology. Psychological Bulletin, 1967, 67, 145-151.

WIENER, M., \& MEHRABIAN, A. Language within language: Immediacy, a channel in verbal communication. New York: Appleton-Century-Crofts, 1968.

(Received July 10, 1968) 